\title{
Effect of weep hole and cut-off wall on hydraulic gradient and uplift pressure under a diversion dam
}

\author{
GHORBAN MAHTABI ${ }^{1, *}$ and FARSHID TARAN ${ }^{2}$ \\ ${ }^{1}$ Department of Water Engineering, University of Zanjan, Zanjan 45371-38791, Iran \\ ${ }^{2}$ Department of Water Engineering, University of Tabriz, Tabriz 51666-16471, Iran \\ e-mail: ghmahtabi@gmail.com; farshidtaran@gmail.com
}

MS received 23 November 2017; revised 16 January 2019; accepted 4 February 2019; published online 25 March 2019

\begin{abstract}
In hydraulic structures such as diversion or gravity dams constructed on a porous foundation, the difference in water levels between upstream and downstream results in water seepage through the porous soil under the dam. This seepage flow generates uplift pressure under the structure that may cause a crack on the concrete surface of the structure's floor. In this condition, the exit gradient may exceed the critical value and cause the piping phenomenon. In this study, the effect of the weep hole and cut-off wall on the uplift pressure and the hydraulic gradient under a diversion dam was investigated experimentally and numerically. For this purpose, four weep holes (diameter $=1 \mathrm{~cm}$ ) were embedded along the longitudinal axis of the stilling basin. The weep holes were examined in single and combined modes. The experiments were conducted in three upstream water heads of 10,15 , and $20 \mathrm{~cm}$. The results showed that in terms of seepage losses, hydraulic gradient, and uplift pressure, the binary combinations of weep holes are better than the other modes. Among the binary combinations, the combination of the two closest weep holes to the dam toe (weep holes 1 and 2) had the most proper performance. In the supplementary experiments, a cut-off wall in two depths $(10$ and $15 \mathrm{~cm})$ was placed at the dam heel in addition to the best modes of weep holes combination. Overall, the simultaneous use of cut-off wall (especially $15 \mathrm{~cm}$ ) and weep holes improved the hydraulic condition of seepage phenomenon under the dam.
\end{abstract}

Keywords. Cut-off wall; hydraulic gradient; seepage; uplift pressure; weep hole.

\section{Introduction}

Hydraulic structures constructed on pervious foundations, in which there is the possibility of water seepage through the bottom of the structures, are exposed to uplift pressure caused by the difference in water heads between the upstream and the downstream. The more the stored water is in the upstream, the more seepage can occur, which leads to a more force posed to the interface of the structure and the foundation. Figure 1(a) shows the uplift pressure distribution under a diversion dam and its stilling basin. In such a condition, the uplift pressure can overturn the structure around its toe or cause a crack on the concrete surface of the structure's floor. Therefore, construction of these structures needs high attention, due to the instability caused by the water seepage [1]. Thus, the force posed on the whole structure and foundation as well as the exit hydraulic gradient in the downstream should be calculated. The most important ways to reduce the uplift pressure is the construction of a cut-off wall in upstream, installation of drains under the structure, and install a weep hole in downstream.

*For correspondence
The cut-off is a barrier of impervious material, usually made of concrete or steel sheet, located in the foundation beneath a dam to reduce seepage under and adjacent to the dam. This wall increases the hydraulic gradient in upstream and decreases it in downstream. As a result, the maximum gradient occurs at the wall location [2]. The weep hole is an opening or a vertical pipe that passes through the apron of the dam, connecting the foundation to the atmosphere. The exterior part of the weep hole is covered by a filter to prevent the fine particles from entering into it. The weep hole decreases the uplift pressure underneath the apron and affects the distribution of the uplift pressure and hydraulic gradient.

A limited number of studies have been conducted on the effect of the cut-off wall and weep hole in the reduction of the seepage underneath the dam. For example, El-Razek and Elela [3] performed a group of experiments to determine the optimum location of the drainage gallery underneath a gravity dam. This location was denoted by the position of the maximum reduction in uplift force, which was found in the middle of dam floor $(l / L=0.5$, where $l$ is the distance from dam toe and $L$ is the length of stilling basin). Chahar [4] obtained explicit equations for 


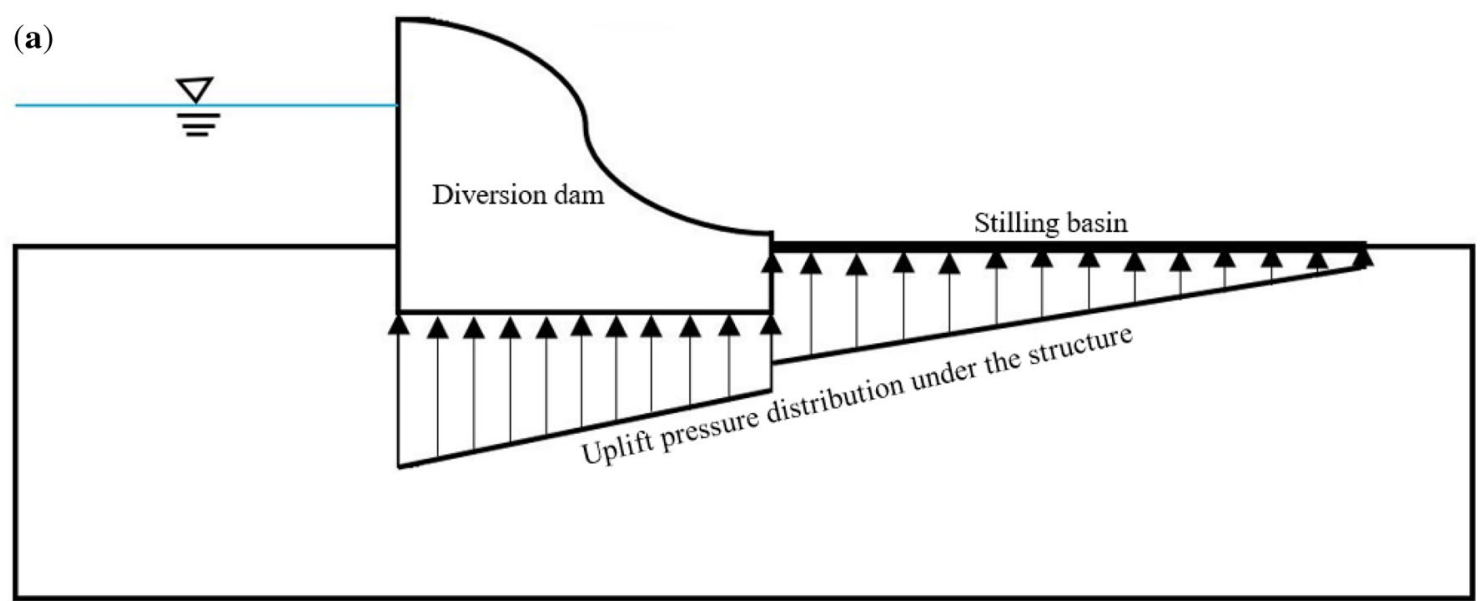

(b)

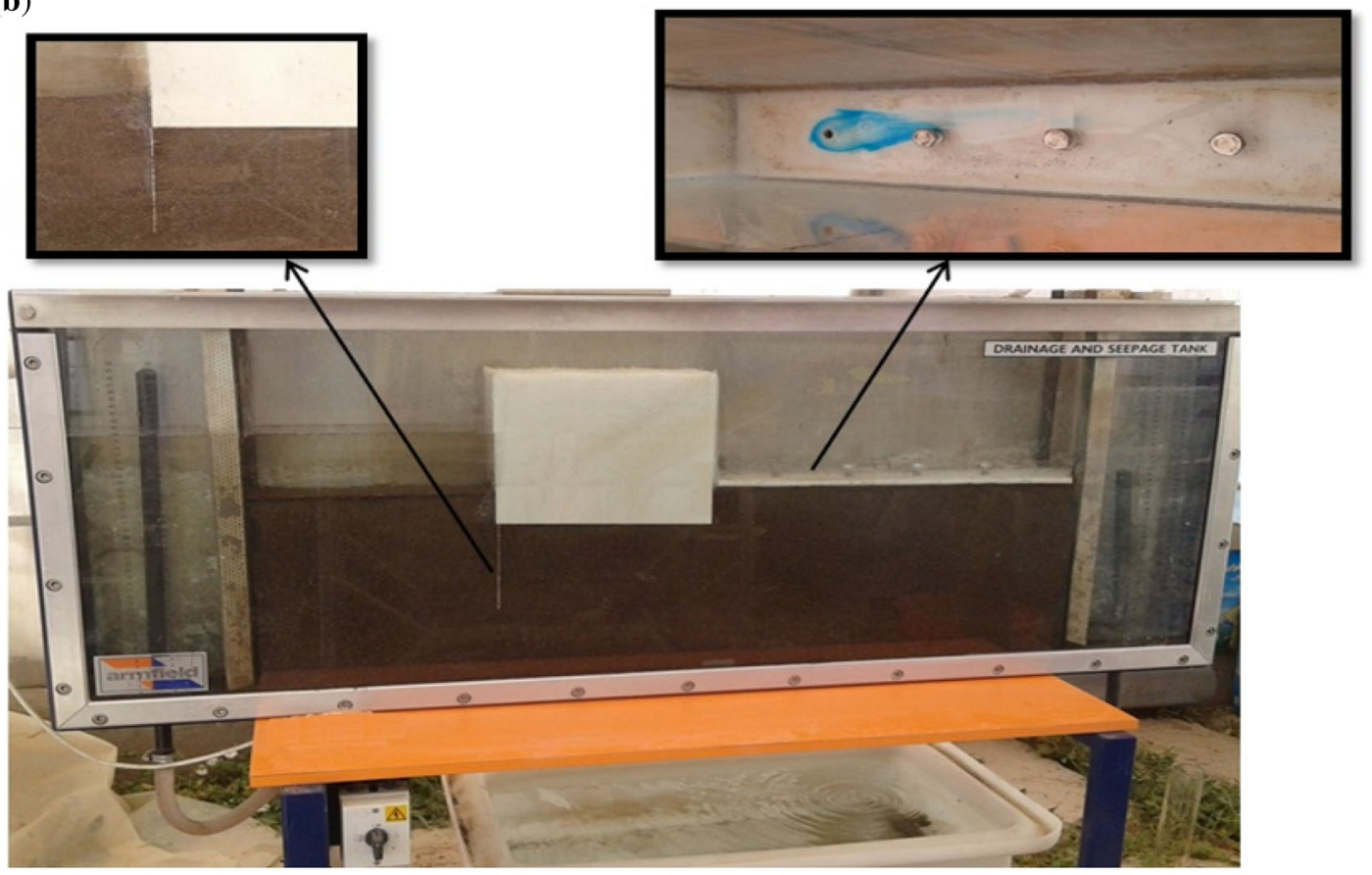

Figure 1. (a) The schematic diagram of the uplift pressure under the structure and (b) the physical model: seepage tank, dam, stilling basin, weep holes on the apron, exit of water from the weep hole \#1, and the location of cut-off wall.

calculating the length of the horizontal drains in the downstream of isotropic and anisotropic earth dams. Da Silva [5], using a nonlinear 3D finite element model (FEM), investigated the influence of the number and position, diameter, spacing, and length of drains on the uplift pressures in a dam on homogeneous and isotropic material. He concluded that the drain length causes the greatest reductions in the uplift pressures, followed by its spacing and diameter. Chen et al [6] presented a FEM numerical model for solving the seepage problem by the drainage systems in dams. Pakbaz et al [7], using the Seep-3D model, investigated the integrity of plastic concrete cut-off wall in the left and right abutments of the Karkheh earth dam in Iran to reduce the seepage flow. They concluded that by constructing the left and right cut-off walls, the seepage amount decreases up to 20 and $60 \%$, respectively. Sabbagh Yazdi and Bayat [8] presented the 2D Nasir software for modeling the seepage in the foundation of concrete weight dams with the cut-off wall. The model uses the numerical model of Galerkin-finite volume for estimation of the uplift pressure in homogeneous and isotropic foundations. $\mathrm{Yu}$ et al [9] investigated the seepage flow of the Fengman dam. They analyzed various factors affecting the seepage flow such as the parameter of concrete, the cut-off wall, the permeability coefficient of the cut-off wall, the drainage hole, and the grout curtains. It was observed that leakage occurs under the main grout curtain and, thus, it is not effective. For this reason, they recommended using a cutoff wall instead of the grout curtain. Azizi et al [10], using the Seep/W software, numerically investigated the effect of 
the weep hole and cut-off wall on uplift pressure in the Yusef-Kand of Mahabad, Iran. They studied the effect of various locations of weep hole and the various depths of the cut-off wall on the amount of uplift pressure as well as exit hydraulic gradient. The results showed that the closer the location of the weep hole is to upstream, the more significant is the reduction of the uplift pressure. Mansuri and Salmasi [11] investigated the effect of horizontal drain and cut-off wall in decreasing the seepage from a hypothetical heterogeneous earth dam. They tried various lengths of the horizontal drain as well as various depths of the cut-off wall in various locations under the dam foundation. They analyzed the seepage flow, hydraulic gradient, and uplift pressure using the Seep/W model. The results showed that increasing the horizontal drain length slightly result in an increase in the seepage rate and the hydraulic gradient. The optimum location of the cut-off wall for decreasing the seepage rate was in the middle of the dam foundation. By increasing the depth of the cut-off wall, the seepage from dam and foundation decreased. Various locations of the cut-off wall in dam foundation had little effect on exit gradient. Installation of the cut-off wall in the middle of the foundation caused $19.68 \%$ reduction in hydraulic gradient compared to the case in which the cut-off wall was placed in the upstream. Obead et al [12], through a FEM numerical analysis, studied the variation of uplift pressures upon the base of typical water retaining structure. They investigated the effect of the position of single and dual drainage holes on uplift pressures. The results showed that the desired reduction in hydraulic uplift pressure could happen using two drainage holes at equidistance of $8 \mathrm{~m}$ from the upstream edge of the structure floor (the average reduction ranged from $1.40 \mathrm{~m}$ to $2.77 \mathrm{~m}$ ).

To our knowledge, the simultaneous effect of weep hole and cut-off wall on seepage underneath earth dams and reduction of uplift pressure in these structures has not been studied in laboratory conditions. Indeed, the studies in this field have been limited to numerical simulations with hypothetical data. In this study, the effect of weep hole and cut-off wall on seepage underneath a diversion dam and reduction of uplift pressure was investigated using a physical and a numerical model. For this purpose, the weep holes were embedded in various locations of stilling basin in the dam upstream, and the cut-off wall was placed in various depths of the dam foundation. The distribution of the uplift pressure and the hydraulic gradient was obtained by the Seep/W software.

\section{Materials and methods}

\subsection{Laboratory model}

In this study, the experiments were conducted in a laboratory seepage tank. This physical model included a cubeshaped box with $150 \mathrm{~cm}$ length, $10 \mathrm{~cm}$ width, and $60 \mathrm{~cm}$ height, a 100 liter water supply reservoir, and a pump with a power of $4 \mathrm{~kW}$. The porous medium used in the experiments was natural sand. The soil optimum moisture and the optimum energy for the soil compaction were determined by the standard Proctor test. Also, the hydraulic conductivity was obtained from the constant head method after bringing the soil to the optimum compaction. The mean grain diameter, optimum moisture, and hydraulic conductivity of the porous medium were equal to $0.55 \mathrm{~mm}, 10.5 \%$, and $0.00025 \mathrm{~m} / \mathrm{s}$, respectively. To establish the constant water head relative to the soil surface at the dam upstream $\left(h_{1}\right)$, the left-hand reservoir of the physical model (figure 1b) was used. In order to calm the water flow from this reservoir into the soil box, a grid plate was placed between the two sections as a filter. Three water heads $\left(h_{1}\right)$ of 10,15 , and $20 \mathrm{~cm}$ were used in the upstream. The soil was packed in the middle part of the seepage tank with a length of $115 \mathrm{~cm}$. First, the soil was wetted to the optimum value and then packed with $10 \mathrm{~cm}$ thick layers to reach the height of $30 \mathrm{~cm}$. This was carried out under the same compaction energy in the standard Proctor test and the same hydraulic conductivity in the constant head method. The diversion dam model made of Plexiglas, with the length of $30 \mathrm{~cm}$ and the height of $27 \mathrm{~cm}$, was installed at a distance of $30 \mathrm{~cm}$ from the beginning of the middle part so that the length of the dam foundation was equal to $5 \mathrm{~cm}$. A Plexiglas plate with a length of $55 \mathrm{~cm}$ and a thickness of $1 \mathrm{~cm}$ was used as a horizontal apron (stilling basin) in the downstream, the upper surface of which was at the same level with the upstream floor. Four weep holes with a diameter $(D)$ of $1 \mathrm{~cm}(0.05 \leq D / \Delta h \leq 0.1)$ were embedded in the apron at the intervals $(l)$ of $10 \mathrm{~cm}(l / L=0.2,0.4,0.6$, and 0.8$)$. Obead et al [12] used similar diameter and intervals in their numerical study $(0.03 \leq D / \Delta h \leq 0.127$ and $l / L=0.25$, 0.75). At the downstream (at the end of the apron), a reservoir was placed for collecting and measuring the seepage water flux under the dam. A grid plate was placed before the collecting reservoir. In order to create the greatest difference between the water heads of upstream and downstream $\left(\Delta h=h_{1}-h_{2}\right)$, the water head in downstream was kept constant at the same level as the apron $\left(h_{2}=0\right)$.

In each experiment, all the weep holes were first closed using screws. After stabilizing the water head at the upstream, one or more screws were opened (depending on the purpose of the experiment). After elapsing time and stabilizing the seepage, the seepage flux was measured in the downstream using a gauged container with a volume of $250 \mathrm{~cm}^{3}\left( \pm 2 \mathrm{~cm}^{3}\right)$. The experiment was conducted with different singles and multiple combinations of the weep hole. In order to increase the accuracy of the results, each experiment was repeated in triplicate and their average was considered as the seepage flux of each experiment. Considering the three upstream water heads, four weep holes as well as their combination modes, and the supplementary experiments with the presence of the cut-off wall and also 
replications, a total of 162 experiments were conducted. In the experiments with the presence of the cut-off wall, a Plexiglas plate with a thickness of $4 \mathrm{~mm}$ as a wall was placed in the dam heel at the two different depths of 10 and $15 \mathrm{~cm}$. In order to change the depth of the cut-off wall, first, the soil was trenched to the relevant depth. After placing the cut-off wall inside the trench, the soil was filled again around the cut-off wall and was compacted. Figure 1(b) shows the physical model containing the seepage tank, the dam, the apron of the stilling basin, the weep holes, and the cut-off wall.

\subsection{Numerical model}

Use of the numerical models can help to better analyze the seepage through the porous media, due to the limitations of the physical models in such studies. In this research, the Seep/W model from the GeoStudio software was used for this purpose. This model is a powerful and comprehensive computer program in the field of seepage analysis and estimation of uplift pressures and hydraulic gradient in porous media. In this program, the seepage equation can be solved under various boundary conditions by the FEM technique. This equation, called the Laplace equation, for a two-dimensional steady flow is as follows [13]:

$$
\frac{\partial}{\partial x}\left[k_{x} \frac{\partial \varphi}{\partial x}\right]+\frac{\partial}{\partial y}\left[k_{y} \frac{\partial \varphi}{\partial y}\right]=0
$$

where $\varphi$ is the water potential in soil and $k_{x}$ and $k_{y}$ are the soil hydraulic conductivity in the directions of $x$ and $y . \varphi$ is indeed the sum of piezometric pressure or pore water pressure (the cause of uplift pressure) and gravity potential. In a homogeneous and isotropic porous mium, it assumed that $k_{x}$ and $k_{y}$ are the same. For the simulation, first, the geometry of the porous medium was drawn in the Seep/W software. Then, the appropriate boundary conditions were applied. At the left-hand vertical line as well as the soil surface at the upstream, a constant potential (the upstream water head + the thickness of the soil layer) was applied. The boundary condition at the right-hand vertical line as well as the surface of the stilling basin was also considered as a constant potential and equal to the thickness of the soil layer (i.e., $30 \mathrm{~cm}$ ). The remaining were considered as impermeable boundaries. The weep holes, when were open, were considered as seepage points and the cut-off wall was considered as an impermeable interface. In order to simulate the seepage flow, the geometry was meshed by square elements. Using a trial and error method and after calibrating the numerical model by the experimental results, the optimal number of the elements were obtained equal to 1441. In order to compare the simulated seepage flux with the experimental values and to evaluate the efficiency of the numerical model, the relative error percentage formula was used:

$$
E \%=\frac{Q_{\text {exp }}-Q_{\text {sim }}}{Q_{\text {exp }}} \times 100
$$

where $Q_{\text {exp }}$ and $Q_{\text {sim }}$ are the experimental and simulated seepage flux, respectively.

\section{Results and discussion}

\subsection{Weep holes}

3.1a Seepage: In this section, the results of the experimental model including the effect of the weep holes on the seepage flow underneath the dam are presented. Figure 2 shows the increment percentage of the seepage flux (IPS) underneath the dam in the various arrangements of the weep holes in the three upstream water heads. According to this figure, the combined modes of weep holes have more seepage flux than the single ones. The seepage flux increases by increasing the upstream water head while decreases by increasing the distance of weep holes from the dam toe. When the weep holes are open singly, the maximum and minimum seepage flux is for weep holes \#1 and $\# 4$, respectively. These two weep holes were respectively at the nearest $(l / L=0.2)$ and furthest $(l / L=0.75)$ distances from the dam toe. In the binary combination, the IPS is less than the sum of the IPS of the two singular weep holes. For example, the IPS of the combination \#1\#2 is 30.35 , while those of the \#1 and \#2 are 23.80 and 18.45, respectively $(30.35<23.80+18.45)$.

In the binary combination, the maximum and minimum seepage flux belongs to the combination \#1\#2 and \#3\#4,

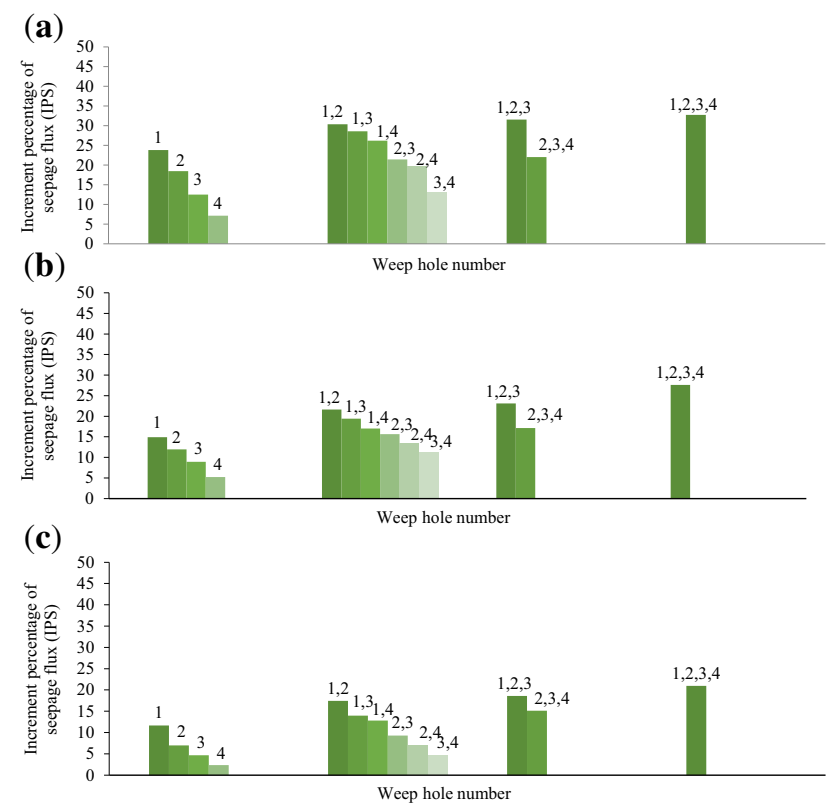

Figure 2. Changes in seepage flux under the dam in various arrangements of the weep holes in the three upstream water heads of (a) $20 \mathrm{~cm}$, (b) $15 \mathrm{~cm}$ and (c) $10 \mathrm{~cm}$. 
respectively. The seepage flux in the binary combinations of weep hole \#2 shows a significant decrease compared to those of weep hole \#1. In general, by increasing the number of weep holes in the combinations, no significant IPS can be observed and, thus, it has an asymptotic trend. In other words, there is no much difference between the binary, ternary, and quaternary combinations. In the ternary combinations, the incremental effect of the weep hole \#1 and the decremental effect of the weep hole \#4 on the seepage flux are quite obvious as in figure 2. It can be stated that the effect of the combination of the weep holes is not cumulative on increasing the seepage and, generally, the weep holes \#1 and \#2 have a dominant effect in increasing the flux. Salmasi and Mansuri [14] numerically investigated the effect of drains on uplift pressure reduction underneath the Tabriz diversion dam. They stated that the seepage flux increases with increasing the diameter or number of drains, but this increase is not cumulative. El-Razek and Elela [3] determined the optimum location of the drainage gallery underneath the gravity dam at $l / L=0.5$, at which seepage discharge entering the drainage gallery is maximum. However, it should be noted that although the increase in the number of weep holes could lead to a better result, it is not often cost-effective. Also, the increase in seepage causes uplift pressure reduction. Therefore, the acceptable seepage or the number of weep holes should be made according to the dam stability and its hydraulic conditions after the economic considerations.

To evaluate the efficiency of the numerical model to ensure accurate estimation of uplift pressure and hydraulic gradient at the various locations under of the dam, the experimental values of seepage flux were compared with the simulated ones. According to figure 3 , there is a good agreement between the experimental $\left(Q_{\text {exp }}\right)$ and numerical $\left(Q_{\text {sim }}\right)$ values of seepage flux with a coefficient of determination of 0.981 and a mean relative absolute error of $4.22 \%$. Nasr et al [15] used a tile drain behind the canal lining to reduce the uplift pressure. They stated that the maximum difference between numerical results and experimental readings is within the range of $10 \%$. Also, Nayeb Asadollah et al [16] simulated water seepage from the Lar dam reservoir using FEM and obtained a very close relation between estimated and observed discharge. A favorable agreement between experimental and numerical results implied the applicability of computer programs to find the solution of seepage problems.

3.1b Hudraulic gradient: Figure 4 presents the values of the hydraulic gradient at the location of each weep hole in the single and combined modes obtained from the numerical model. The horizontal axes together with the numbers on the columns represent the various combinations of a weep hole with the others. The columns with the same color represent the combinations of weep holes. The columns with no number represent the single weep holes (gray columns). For each weep hole, the highest hydraulic gradient is related to the single mode. Among the four weep holes in the single mode, the weep hole \#1 has the highest hydraulic gradient. The hydraulic gradient in the weep hole \#4 is about $40 \%$ less than weep hole \#1. In general, by increasing the distance of weep holes from the dam toe, the hydraulic gradient has decreased in both the single and combined modes. Azizi et al [10] concluded that the closer the location of the weep hole is to upstream, the higher is the hydraulic gradient at the weep hole. In their study, the hydraulic gradient at the end weep hole $(l / L=1)$ decreased by about $61 \%$ compared to the beginning one $(l / L=0.25)$.

Among the binary combinations of the weep hole \#1, the lowest hydraulic gradient occurs when the weep hole \#2 is open at the same time as the weep hole \#1. Also, it is observed that the hydraulic gradients of weep hole \#1 combinations do not change significantly as the number of weep holes increases (in the combination \#1\#4, 3.5\% reduction compared to the combination \#1\#2). In the weep hole \#2, the lowest hydraulic gradient of the binary combination is related to $\# 1 \# 2$, which is about $51 \%$ less than its (a)

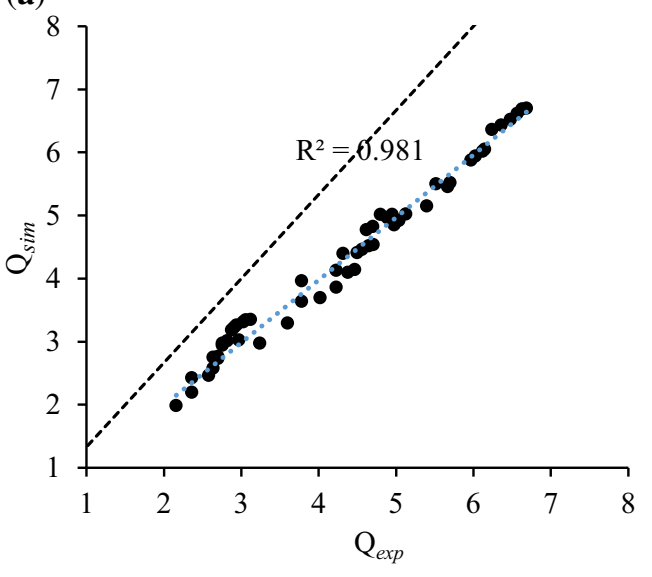

(b)

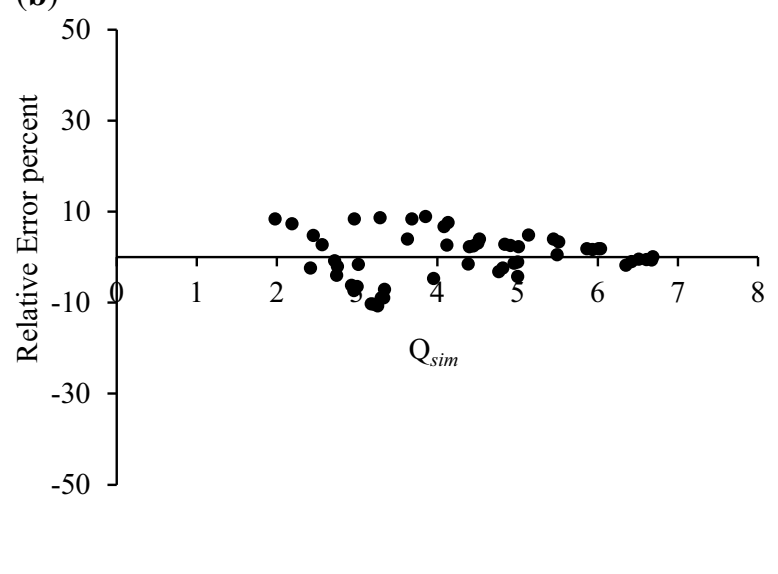

Figure 3. (a) The fitting curve of the experimental and simulated seepage fluxes and (b) the numerical model relative error. 

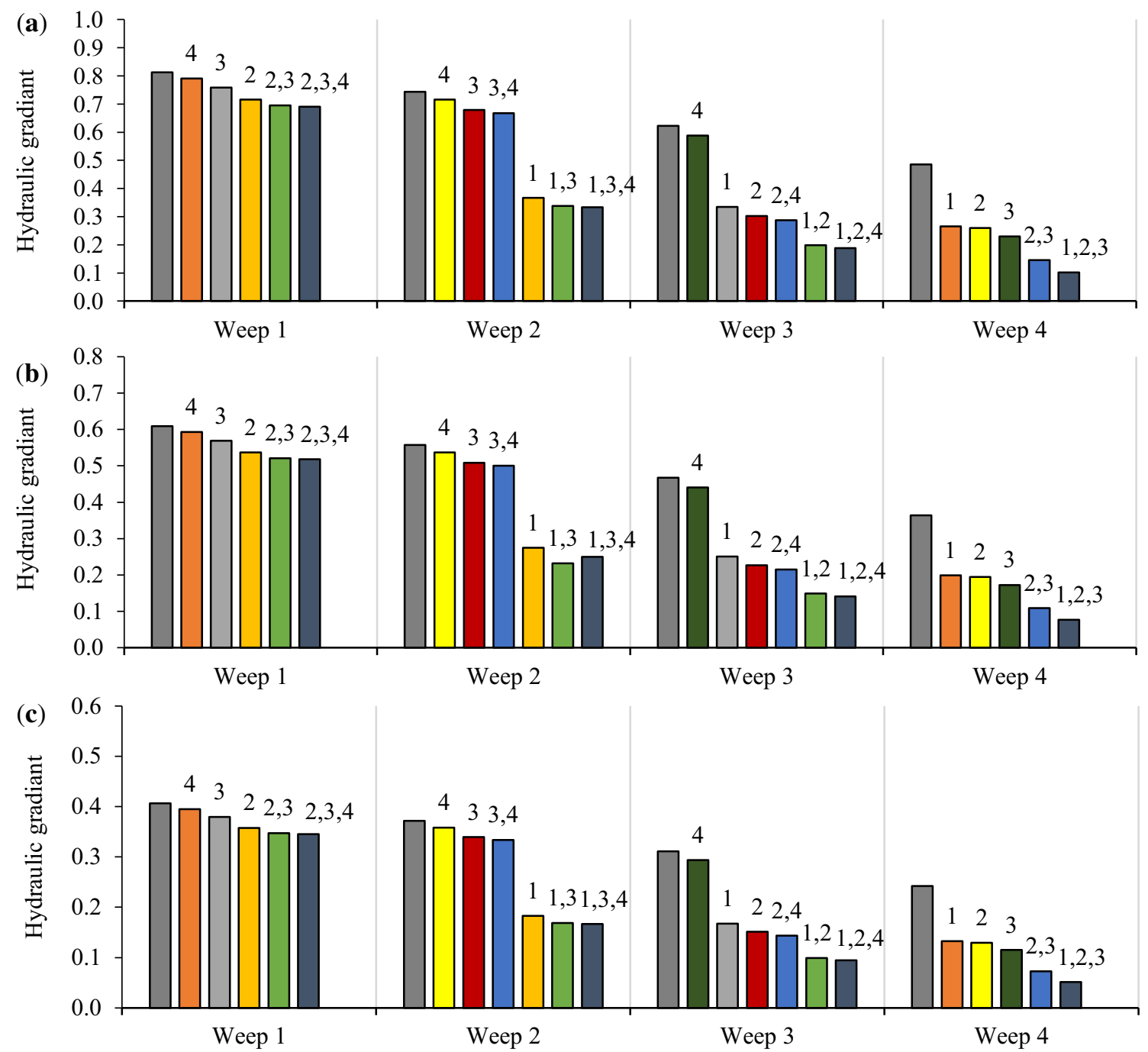

Figure 4. The values of hydraulic gradient at the locations of weep holes in single and combined modes in the three upstream water heads of (a) $20 \mathrm{~cm}$, (b) $15 \mathrm{~cm}$ and (c) $10 \mathrm{~cm}$.

single mode. In combination mode of $\# 1 \# 2$, the hydraulic gradient of weep hole \#1 decreases about $12 \%$ compared to the single mode of \#1. In the ternary and quaternary combinations of weep hole \#2 (i.e., \#1\#2\#3 and \#1\#2\#3\#4), the amount of hydraulic gradient is almost constant with a slight reduction. However, in the combinations of the weep hole \#2 with the weep hole \#3 or \#4, due to the increase in distance of these two weep holes from the dam toe, the hydraulic gradient at the location of the weep hole \#2 increases significantly (about $85 \%$ increase compared to the combination \#1\#2). In the weep hole \#3, the lowest hydraulic gradient among the binary combinations belongs to the combination $\# 2 \# 3$, which was decreased about $51.4 \%$ compared to the single mode of the weep hole \#3. Among the ternary combinations, the combination \#1\#2\#3 has a lower hydraulic gradient. In the weep hole \#4, there is no considerable difference between the binary combinations. However, the least gradient belongs to the combination \#3\#4 with about $52.6 \%$ reduction compared to the single mode of the weep hole \#4. By increasing the number of weep holes in combination with the weep hole \#4, the hydraulic gradient at the location of this weep hole has decreased and has reached its minimum value in the combination \#1\#2\#3\#4.

Figure 5 presents the values of hydraulic gradient in the downstream of the stilling basin for all the single and combined modes obtained from the numerical model. According to this figure, the downstream hydraulic gradient is almost equal in the single modes of weep holes. The values have decreased $45.4 \%$, on average, relative to the when none of the weep holes are open. Azizi et al [10] concluded that the existence of a weep hole in the stilling basin could reduce the hydraulic gradient in downstream by about $57 \%$.

In the binary combinations, the downstream hydraulic gradient has a significant reduction compared to the single modes, but such a reduction is not so much about the ternary and quaternary combinations. In the binary combinations, 


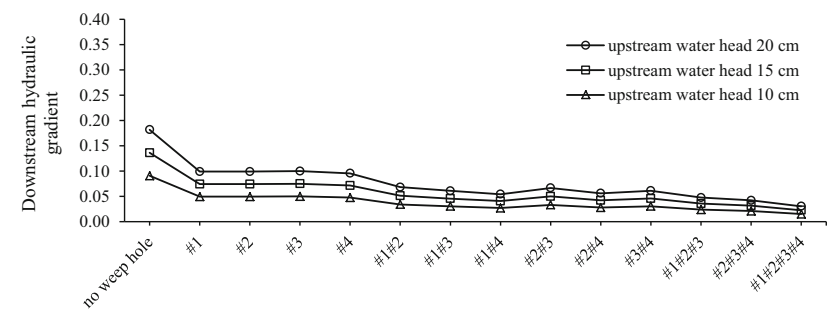

Figure 5. The values of hydraulic gradient in the downstream of stilling basin in the three upstream water heads.

the minimum downstream hydraulic gradient belongs to the combinations \#1\#4 and \#2\#4 with a reduction of about $70 \%$ compared to the no-weep hole mode. However, there is no significant difference between the downstream hydraulic gradient for the binary combinations. In hydraulic structures, one or more cut-off walls are used at the downstream to control the hydraulic gradient. In the research of Moharrami et al [17], upstream cut-off wall decreased the downstream hydraulic gradient by about $15 \%$, while an about $50 \%$ reduction was observed by using the downstream cut-off wall. Based on the results of the present study, it seems that the weep hole can perform the task of a downstream cut-off wall properly. This positive effect of weep hole is more remarkable in its combined modes.

In the single modes of weep holes, the value of exit hydraulic gradient is high and, therefore, a filter must be used in the location of the weep holes to prevent the formation of sand boil phenomenon. Also, in the single modes of weep holes, compared to the combined modes, the downstream hydraulic gradient is somewhat high. However, in order to reduce the seepage losses and also from the economic standpoint, it is better to use a fewer number of weep holes. Considering the insignificant difference in the effect of the binary and ternary combinations of weep holes on the amount of hydraulic gradient in the location of weep holes and the downstream, it can be stated that the binary combinations are the best choice for controlling the hydraulic gradient. Such a choice has the most effect on the reduction of uplift pressure with minimum seepage.

3.1c Uplift pressure: Figure 6 illustrates the decrement percentage of the uplift pressure (DPU), obtained from the numerical model, for the single and combined modes. In general, by increasing the distance of weep holes form the dam toe, the uplift pressure increases. In the single modes, the maximum and minimum reductions of uplift pressure were observed at the weep holes \#1 (39.6\% reduction) and \#4 (10.5\% reduction), respectively. Azizi et al [10] concluded that installation of a weep hole at the downstream of stilling basin $(l / L=0.75)$ reduces the uplift pressure by about 20\%. They also reported that the more weep hole position is closer to the upstream, the more reduction of uplift pressure will be. As shown in figure 6, by combining the weep holes and increasing the upstream water head, the decrement percentage of uplift pressure (DPU) increases. In the binary combinations, the combinations belonged to the
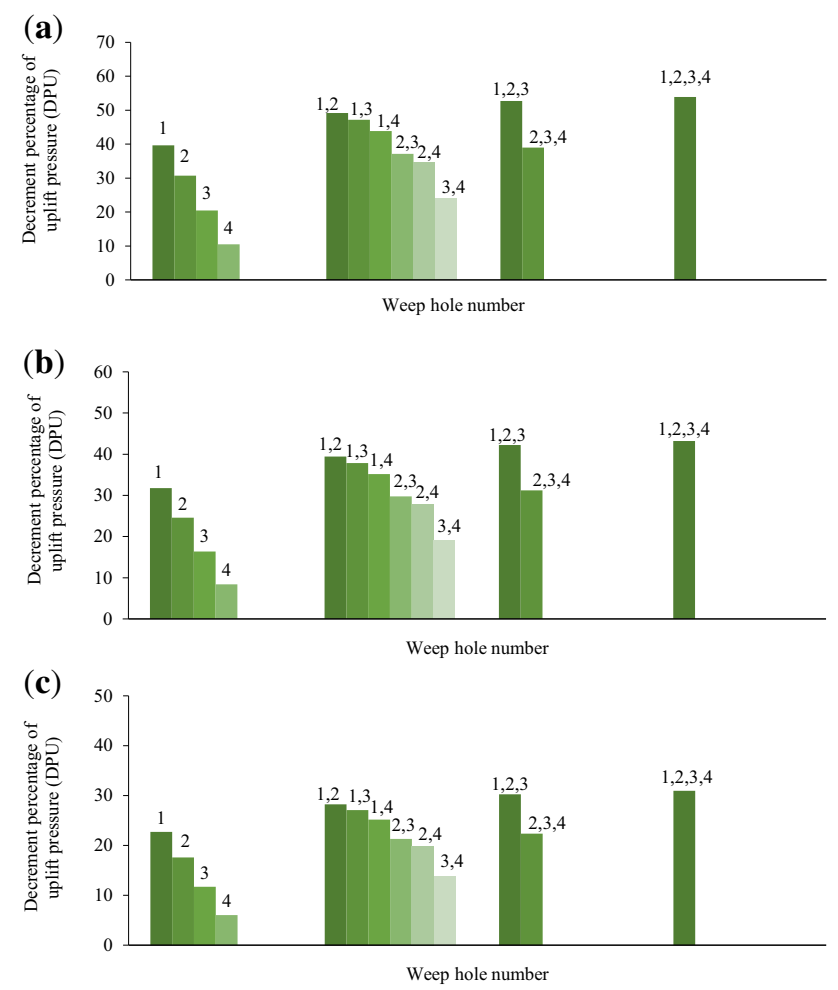

Figure 6. Changes in the uplift pressure under the structure in the various arrangements of weep holes in the three upstream water heads of (a) $20 \mathrm{~cm}$, (b) $15 \mathrm{~cm}$ and (c) $10 \mathrm{~cm}$.

weep hole \#1 (i.e., \#1\#2,\#1\#3, and \#1\#4) have the greatest effect on the reduction of uplift pressure (about 43.8-49.2\% reduction in the highest upstream water head, which is $20 \mathrm{~cm}$ ). Obead et al [12] used double drainage holes located on the dam base centerline $(l / L=0.5$ and 0.75$)$ and found that the reduction of the uplift pressure was equal to $48 \%$. Also, the effect of transverse spacing was smaller than the longitudinal distance of drainage holes on the reduction of the uplift pressure. In the best-combined mode (\#1\#2), compared to the single mode of weep hole \#1, the uplift pressure has decreased by about $24 \%$. The effect of the binary combinations \#2\#3 and \#3\#4 on uplift pressure is almost the same and the binary combination \#3\#4 has the least effect on reducing the uplift pressure (13.7-23.9\% reduction in $20 \mathrm{~cm}$ upstream water head). By increasing the number of weep holes (the ternary and quaternary combinations), the DPU does not change significantly. So, the combinations \#1\#2\#3 and \#1\#2\#3\#4 compared to the combination $\# 1 \# 2$ have only $7 \%$ and $9.6 \%$ higher effects on the uplift pressure, respectively. Therefore, it seems that the most favorable result could be obtained from the binary combinations of weep hole \#1.

In terms of the seepage level and downstream hydraulic gradient (minimum seepage loses and gradient), the binary combination \#1\#4 is the best choice. However, in this combination, the hydraulic gradient at the location of weep hole \#1 is larger than that of the other binary combinations (10\%) and is similar to the single mode of weep hole \#1. In 


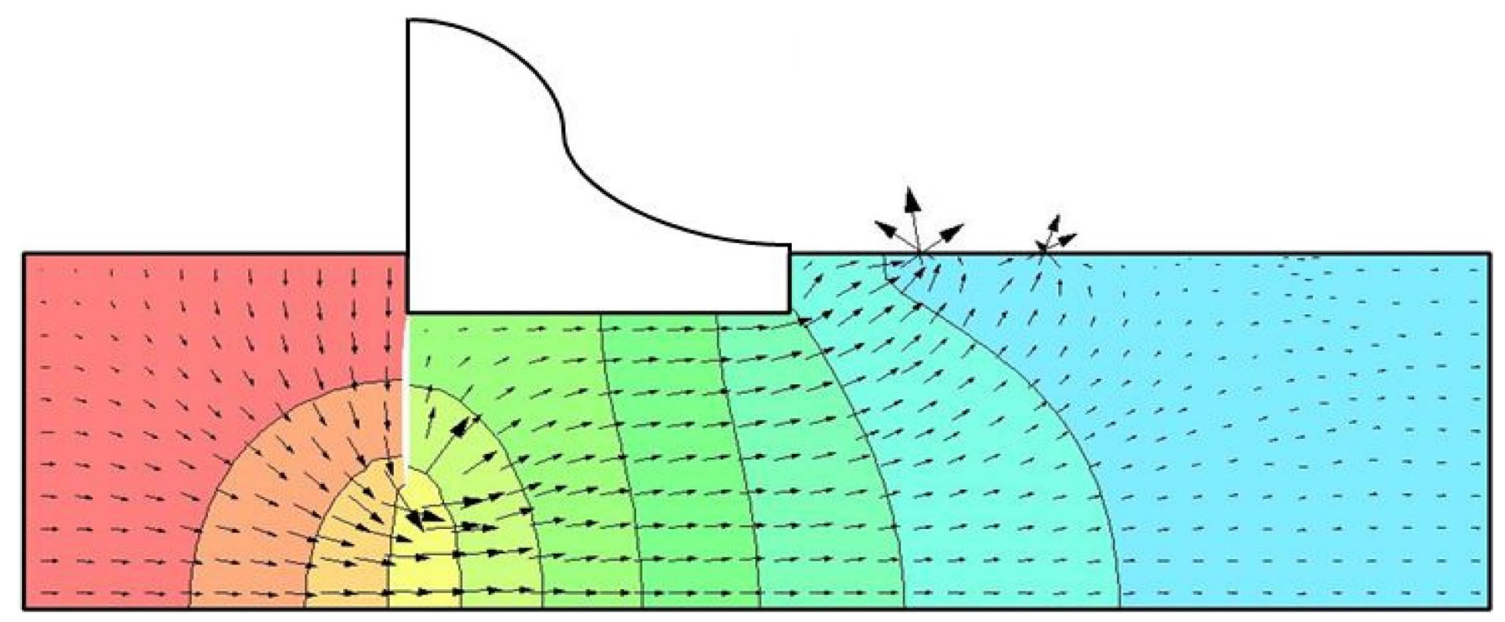

Figure 7. The flow vectors and equipotential contours under the dam in the presence of the cut-off wall (depth of $15 \mathrm{~cm})$ and the weep holes \#1 and \#2.

terms of the amount of exit hydraulic gradient in the weep holes, the binary combination \#1\#2 is the best choice, because, among the binary combinations of weep hole \#1, the smallest hydraulic gradient belongs to this combination. In terms of the reduction of uplift pressure, combination $\# 1 \# 2$ is the best. It is worth noting that the effect of this combination on reducing the uplift pressure is about $12.1 \%$ more than the combination \#1\#4. Considering the necessity of reducing the hydraulic gradient at the location of the weep holes and the importance of reducing the uplift pressure, it seems that the binary combination \#1\#2 can be the most proper choice. However, this is not a definite suggestion and can be discussed further in developmental studies.

\subsection{Weep holes and cut-off wall}

In this section, the experimental and numerical results of the simultaneous effect of the weep hole combination \#1\#2 (as the best mode) and the cut-off wall on the seepage, hydraulic gradient, and uplift pressure are shown. Figure 7 depicts the flow vectors as well as the equipotential contours under the condition of using the cut-off wall $15 \mathrm{~cm}+$ weep hole combination \#1\#2. Figure 8 shows the changes of seepage amount in the experimental model under the above-mentioned conditions. According to this figure, the installation of the cut-off wall has led to a drop in the seepage flow underneath the structure. It is also observed that with increasing the depth of the cut-off wall, the seepage amount is reduced further so that the cut-off wall with the depth of $15 \mathrm{~cm}$ has reduced the seepage amount by about 16.3-25\% compared to the no-cutoff wall mode. Studies on the control of seepage underneath the dam by the cut-off wall indicate that it reduces the seepage amount and with increasing its depth, this decrease becomes more prominent (e.g., Mansuri and Salmasi [11]).

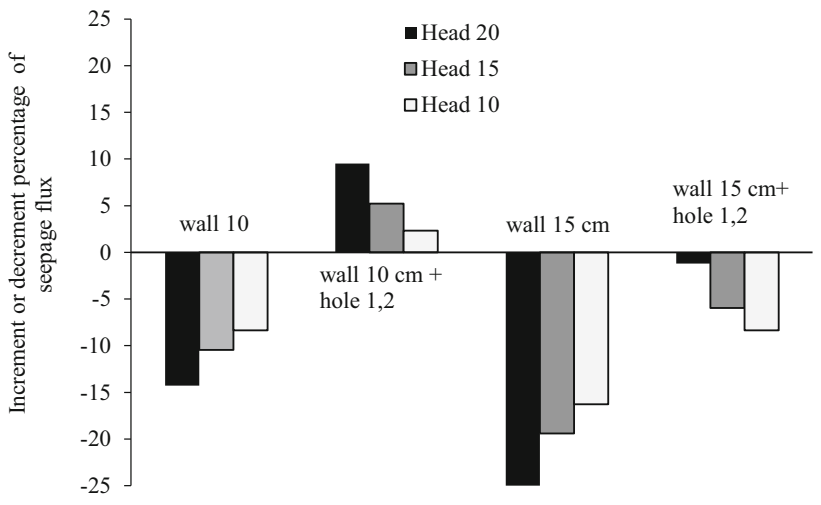

Figure 8. Changes in the seepage flux under the structure due to use of the cut-off wall and the weep hole combination \#1\#2.

It is observed that by simultaneous use of the cut-off wall and the weep hole combination \#1\#2, the effect of weep holes has dominated the effect of the cut-off wall. In other words, the negative effect of weep holes in increasing the seepage amount (water losses) has been more than the positive effect of the cut-off wall in reducing it, which leads to an increase in the seepage amount. However, by increasing the depth of the cut-off wall, the negative effect of the weep hole was reduced and, thus, the seepage amount was decreased again. With all these explanations, it can be concluded that the simultaneous use of cut-off wall and weep hole can be very effective in controlling the seepage losses from the weep holes.

Figure 9 exhibits the effect of the cut-off wall and the weep hole combination \#1\#2 on the values of the hydraulic gradient at various locations (end of the cut-off wall, downstream, and weep holes). The cut-off wall has reduced the hydraulic gradient at the downstream up to $20 \%$ (relative to the no-cut-off and no-weep hole mode). In comparison, the simultaneous use of the weep holes \#1 and \#2 and the cut-off wall has decreased the downstream 

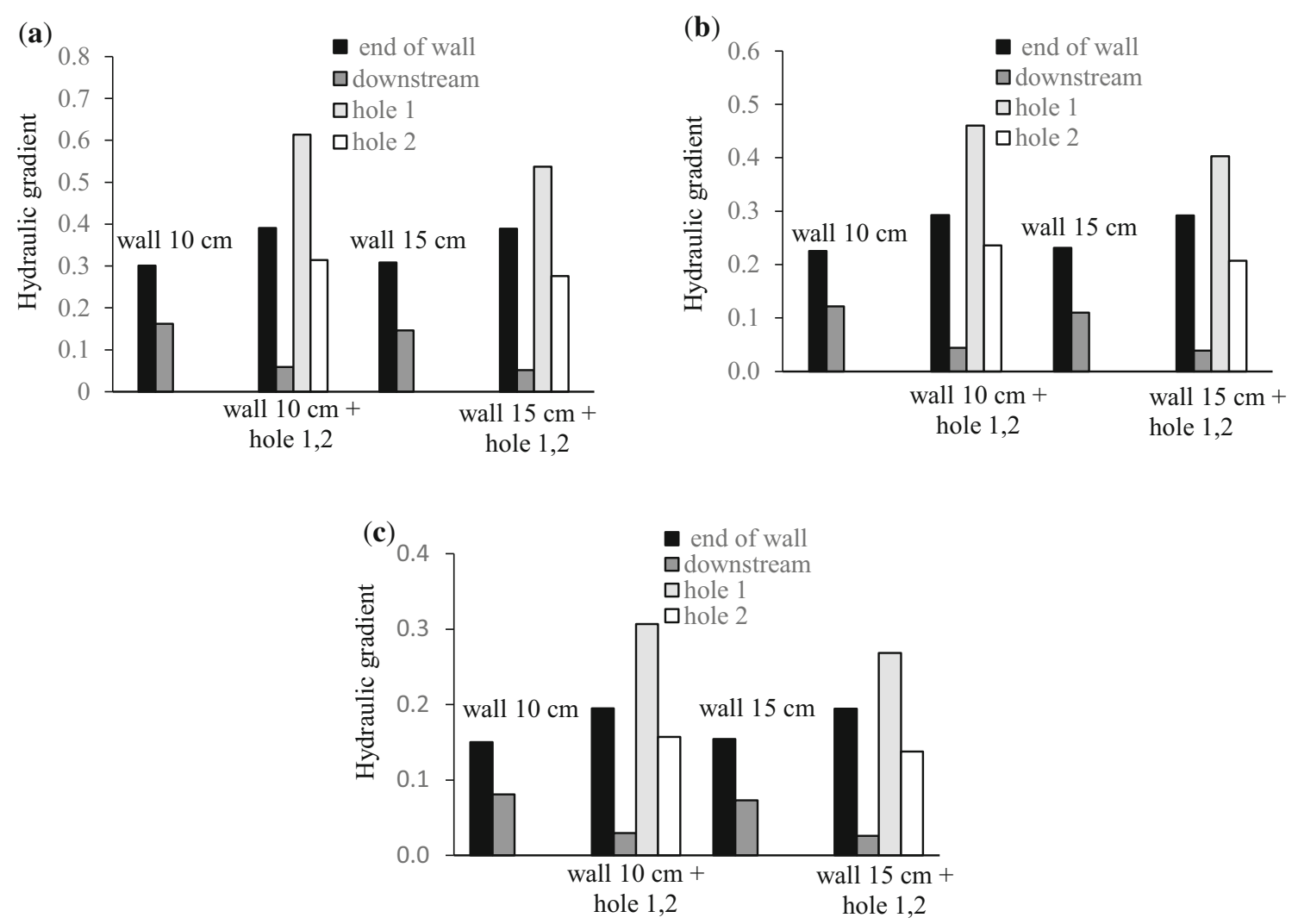

Figure 9. The values of hydraulic gradient at various locations under the condition of use of the cut-off wall and the weep holes \#1 and \#2 in the three upstream water heads of (a) $20 \mathrm{~cm}$, (b) $15 \mathrm{~cm}$ and (c) $10 \mathrm{~cm}$.

hydraulic gradient up to $70 \%$. Moharrami et al [17] concluded that upstream cut-off wall could reduce the downstream hydraulic gradient by about $15 \%$ relative to the no-cut-off wall conditions. Azizi et al [10] stated that simultaneous installation of cut-off wall and weep hole reduces the downstream hydraulic gradient $63 \%$ relative to the no-cut-off and no-weep hole condition. In this study, simultaneous use of cut-off wall and weep holes \#1 and \#2 has reduced the hydraulic gradient at the location of the weep holes $(24.2 \%$ reduction in the weep hole \#1). It seems that the combination of cut-off wall and weep hole has been able to control the negative effects of both of them (seepage losses of the weep hole as well as downstream hydraulic gradient). Also, the hydraulic gradient at the end of the cut-off wall has increased by $30 \%$ in the cut-off wall + weep hole mode relative to the only cut-off wall mode. Azizi et al [10] obtained a similar result (20\% increase).

In figure 10, the DPU is presented for the condition of use of the cut-off wall and the weep holes \#1 and \#2. Under the maximum upstream water head (i.e., $20 \mathrm{~cm}$ ) and use of the cut-off wall with the depth of $15 \mathrm{~cm}$ (half the length of the dam), the uplift pressure was decreased by about $28 \%$ relative to the no-cut-off and no-weep hole mode. The study of Azizi et al [10] indicated that cut-off wall results in

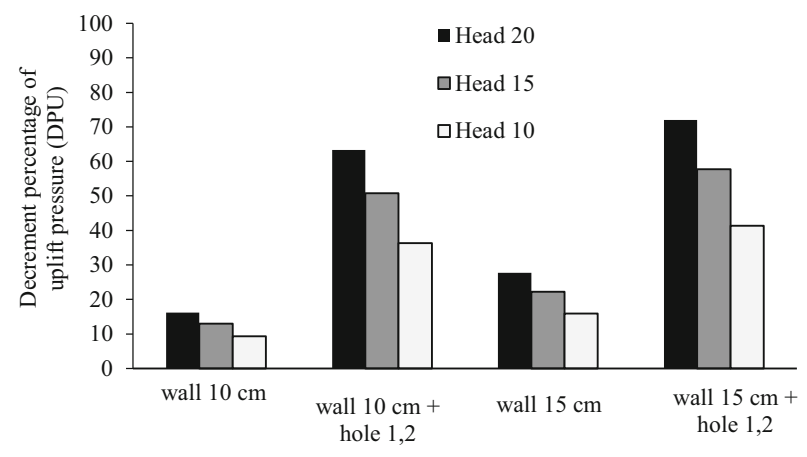

Figure 10. Changes in the uplift pressure under dam due to use of the cut-off wall and the weep hole combination \#1\#2.

a $44 \%$ reduction of uplift pressure under similar conditions. The simultaneous use of the cut-off wall and the weep holes $\# 1$ and \#2 has reduced the uplift pressure by about $72 \%$ under the upstream water head of $20 \mathrm{~cm}$ and use of the cutoff wall with the depth of $15 \mathrm{~cm}$. According to Azizi et al [10], the uplift pressure was decreased by about $66 \%$. ElRazek and Elela [3] and Uday and Hasan [18] determined the optimum location of the drainage gallery underneath gravity dam at which reduction in the uplift pressure was about $54 \%$ and $40 \%$, respectively. 


\section{Conclusion}

In this paper, the effect of the weep hole and cut-off wall on the uplift pressure and hydraulic gradient under a diversion dam was investigated by experimental and numerical models. For this purpose, four weep holes with various combinations and a cut-off wall in two depths were used in stilling basin and dam heel, respectively. The results can be summarized as follows.

- The combined modes of weep holes have more seepage flux than the single ones but the combination modes have no cumulative effect on increasing the seepage.

- There is a good agreement between the experimental and numerical values of seepage flux.

- The hydraulic gradient at the location of weep holes decreases in the combined modes more than the single modes.

- The downstream hydraulic gradient has a significant reduction in the binary combinations compared to the single modes, but this reduction is not observed in the ternary and quaternary combinations.

- By combining the weep holes, the uplift pressure decreases. However, in the ternary and quaternary combinations, the decrement of uplift pressure does not change significantly compared to the binary combinations. In the binary combinations, the combinations belonged to the weep hole \#1 has the greatest effect on the reduction of uplift pressure.

- Based on the results of the seepage flux, the hydraulic gradient, and the uplift pressure, the binary combination \#1\#2 is the most proper choice.

- The simultaneous use of the cut-off wall and the weep hole combination \#1\#2 is very effective in controlling the seepage losses from the weep holes, the downstream gradient, and the uplift pressure.

\section{Nomenclature}

$D \quad$ diameter of weep hole

$h_{1} \quad$ water head in upstream

$h_{1} \quad$ water head in downstream

$k_{x}, k_{y} \quad$ soil hydraulic conductivity in $x$ and $y$ direction

$l \quad$ distance from dam toe

$L \quad$ length of stilling basin

$Q_{\text {exp }} \quad$ experimental seepage flux

$Q_{\text {sim }} \quad$ simulated seepage flux

\section{Greek symbol}

$\Delta h \quad$ difference between $h_{1}$ and $h_{2}$

$\varphi \quad$ water potential in soil

$\partial x, \partial y \quad$ grid size in $x$ and $y$ direction

\section{References}

[1] Nagraj T S and Murthy B R S 1985 Prediction of the reconsolidation pressure and recompression index of soil. Geotech. Test. J. 8: 199-202
[2] Zainal A K E 2011 The effect of cutoff wall angle on seepage under dams. J. Eng. 5: 1109-1131

[3] El-Razek M A and Elela M M A 2002 Effect of drainage gallery dimensions on the uplift force of a gravity dam. $J$. Lowland Tech. Int. 4: 43-50

[4] Chahar Bh R 2004 Determination of length of a horizontal drain in homogeneous earth dams. J. Irrig. Drain. Eng. 130: 530-536

[5] Da Silva J F 2005 Influence of the geometry of the drainage system and of the foundation anisotropy on the uplift pressures under concrete dams. In: $5^{\text {th }}$ Brazilian Symposium on Applications of Computational Mechanics in Geotechnical Engineering, Belo Horizonte, Brazil, pp. $165-174$

[6] Chen Y, Zhou Ch and Zheng H 2008 A numerical solution to seepage problems with complex drainage systems. Comput. Geotech. 35: 383-393

[7] Pakbaz M S, Dardaei A and Salahshoor J 2009 Evaluation of performance of plastic concrete cutoff wall in Karkheh Dam using 3-D seepage analysis and actual measurement. J. Appl. Sci. 9: 724-730

[8] Sabbagh-Yazdi S R, Mastorakis N E and Bayat B 2007 Assessment and application of 3D Galerkin finite volume explicit solver for computation of seepage and uplift in dam foundation. Inter. J. Math. Mod. Meth. Appl. Sci. 1: 285-293

[9] Yu H, Li Sh and Chen Ch 2009 Evaluation and rehabilitation of the seepage problems at the Fengman dam. Electron. J. Geotech. Eng. 14: 1-14

[10] Azizi S, Salmasi F, Abbaspour A and Arvanaghi H 2012 Weep hole and cut-off effect in decreasing of uplift pressure (case study: Yusefkand Mahabad Diversion Dam). J. Civil. Eng. Urban. 2: 97-101

[11] Mansuri B and Salmasi F 2013 Effect of horizontal drain length and cutoff wall on seepage and uplift Pressure in heterogeneous earth dam with numerical simulation. J. Civil. Eng. Urban. 3: 114-121

[12] Obead I H, Al-Baghdadi H M and Hamad R 2014 Reducing the impact of uplift pressures on the base of a concrete dam by configuration of drainage holes (hypothetical case study). Civil. Environ. Res. 6: 120-131

[13] Anonymous 2007 Seepage Modeling with Seep/W. An Engineering Methodology. Third edition: Geo-Slope International Ltd. Calgary, Alberta, Canada

[14] Salmasi F and Mansuri B 2016 Numerical investigation of underground drain radius, depth and location on uplift pressure reduction (case study: Tabriz diversion dam. Azarian J. Agric. 3: 58-65

[15] Nasr R I, Zeydan B A, Bakry M F and Saloom M S 2003 Uplift pressure relief on lined canals using tile drains. Alexandria Eng. J. 42: 497-507

[16] Nayeb Asadollah S, Aalianvari A and Hajialibeigi H 2018 Role of geological structures in seepage from Lar dam reservoir. Arab. J. Geosci. 11: 632

[17] Moharrami A, Moradi Gh, Hajialilue Bonab M, Katebi J and Moharrami Gh 2014 Performance of cut-off walls under hydraulic structures against uplift pressure and piping phenomenon. Geotech. Geol. Eng. 33: 95-103

[18] Uday A M and Hasan H M 2016 Optimal location of drainage gallery under gravity dam by using finite element method. Int. J. Multidiscip. Res. Mod. Educ. 2: 611-622 